\title{
Correction to: A comparison of Structure-Activity of Cu-Modifed Over Diferent Mesoporous Silica Supports for Catalytic Conversion of Levulinic Acid
}

\author{
Balla Putrakumar ${ }^{1} \cdot$ Prem Kumar Seelam $^{2} \cdot$ Ginjupalli Srinivasarao $^{3} \cdot$ Karthikeyan Rajan $^{1} \cdot$ Mitta Harishekar $^{4}$. \\ Keiski Riitta ${ }^{2}$ Tong Xiang Liang ${ }^{1}$
}

Published online: 12 November 2021

(c) Springer Nature B.V. 2021

\section{Correction to: Waste and Biomass Valorization (2021) https://doi.org/10.1007/s12649-021-01485-z}

Following publication of the original article [1], the authors identified an error in the author name of Seelam P.K.

The incorrect author name is: Kumar S.P, The correct author name is: Seelam P.K.

The author group has been updated above and the original article [1] has been corrected.

Publisher's Note Springer Nature remains neutral with regard to jurisdictional claims in published maps and institutional affiliations.

The original article can be found online at https://doi.org/10.1007/ s12649-021-01485-z.

Balla Putrakumar

bputrakumar@yahoo.com

$\triangle$ Prem Kumar Seelam

prem.seelam@oulu.fi

$\bowtie$ Tong Xiang Liang

txliang@jxust.edu.cn

1 Engineering Research Centre for Hydrogen Energy and New Materials, College of Rare Earths (CORE), Jiangxi

University of Science and Technology, Ganzhou 341000,

China

2 Environmental and Chemical Engineering, Faculty of Technology, University of Oulu, P.O. Box 4300, Oulu, Finland

3 Applied Chemistry Section, Department of Applied Sciences, University of Technology and Applied Sciences, P.O. Box 74, P.C 133 Muscat, Oman

4 Catalysis Division, Indian Institute of Chemical Technology, Hyderabad, India 